\title{
CONSERVAÇÃO DE GERMOPLASMA DE FRUTEIRAS TROPICAIS COM A PARTICIPAÇÃO DO AGRICULTOR ${ }^{1}$
}

\author{
PAULO CEZAR LEMOS DE CARVALHO², WALTER DOS SANTOS SOARES FILHO ${ }^{3}$, \\ ROGÉRIO RITZINGER ${ }^{3}$, JOANA ANGÉLICA B. S. CARVALHO ${ }^{4}$
}

\begin{abstract}
RESUMO - A conservação de germoplasma de fruteiras tropicais é uma ação importante contra a erosão genética decorrente de diversas atividades agrícolas que perturbam os ecossistemas em que se verificam, com prejuízos não raro irreversíveis a muitas espécies, particularmente às nativas. A criação e manutenção de coleções a campo de fruteiras perenes é dispendiosa, sendo comum a indisponibilidade de recursos financeiros para esta finalidade. O envolvimento do agricultor neste processo é uma ação estrategicamente importante, pois, além de favorecer a conservação desse germoplasma, estimula a conscientização de sua importância junto às comunidades envolvidas. Com base nisso, duas coleções de fruteiras tropicais foram instaladas em 1995/1996; uma na Escola de Agronomia da Universidade Federal da Bahia, em Cruz das Almas, e outra em duas propriedades rurais no município de São FelipeBA. Vêm sendo conservadas cerca de 30 espécies, principalmente nativas. Algumas iniciaram a frutificação, mostrando-se promissoras quanto ao seu cultivo comercial.
\end{abstract}

Termos para indexação: Annona spp., Averrhoa spp., Eugenia spp., Spondias spp., Achras sapota, Genipa americana.

\section{CONSERVATION OF GERMPLASM OF TROPICAL FRUITS WITH THE FARMER'S PARTICIPATION}

\begin{abstract}
The conservation of germplasm of tropical fruits is an important action against the genetic erosion due to several agricultural activities that disturb the ecosystems in which they occur, with damages no rare irreversible to a lot of species, particularly the native ones. The creation and maintenance of field collections of perennial fruit species are costly, being common the unavailability of financial resources for this purpose. The farmer's involvement in this process is strategically an important action, because, besides favoring the conservation of that germplasm, it also stimulates the understanding of its importance in the communities involved. Based on that, two collections of tropical fruits were installed in 1995/1996: one in the College of Agronomy of the Federal University of Bahia, in Cruz das Almas, and the other in two rural properties in the municipal district of São Felipe, Bahia, Brazil. About 30 species, most of them native, have been conserved there. Some already started producing fruit, showing to be promising regarding its commercial cultivation.
\end{abstract}

Index terms: Annona spp., Averrhoa spp., Eugenia spp., Spondias spp., Achras sapota, Genipa americana

O Nordeste brasileiro apresenta condições climáticas favoráveis ao cultivo de diversas espécies frutíferas de origem tropical, como se pode verificar pela expressiva diversidade de espécies nativas encontradas na região, ao lado de outras, exóticas, introduzidas de ecossistemas equivalentes e que se adaptaram bem, comportando-se de modo semelhante ao do material nativo, a exemplo da jaqueira, fruta-pão, sapotizeiro, mangueira, entre outras.

A exploração de fruteiras nativas no Nordeste do Brasil ocorre na maioria das vezes de forma extrativista, em vista da falta de conhecimento de quem as utiliza, pois muitos não têm noção do que são recursos genéticos e da importância da conservação de germoplasma. Muitas árvores são transformadas em lenha para atender a olarias, casas-de-farinha e padarias, cabendo destacar a redução da biodiversidade provocada pelo desmatamento de áreas com vegetação nativa, visando à formação de pastagens, que, sem dúvida, é o fator responsável de maior importância pela perda de recursos genéticos, tanto de origem vegetal como animal.

A maior parte das espécies frutíferas que se encontram no Nordeste, tanto aquelas cultivadas de forma regular, a exemplo da gravioleira, goiabeira, ateira, aceroleira, cajueiro, mangueira e maracujazeiro, como outras exploradas normalmente de forma extrativista, dentre as quais se encontram o umbuzeiro, umbucajazeira, jenipapeiro, cajazeira, grumixameira, guabirobeira, jabuticabeira, cagaiteira, diversos araticuns, palmeiras e várias outras mirtáceas, apresentam grande escassez ou mesmo ausência de dados relativos à sua morfologia, produção, características fisiológicas e fenologia, importantes para a descrição e caracterização dos diversos genótipos existentes, dados estes que serviriam de base para a incorporação de muitas espécies frutíferas, particularmente estas últimas, aos sistemas produtivos

1 (Trabalho 229/2000). Recebido: 16/10/2000. Aceito para publicação: 18/10/2001. Trabalho apresentado no XVI Congresso Brasileiro de Fruticultura 2 Professor Assistente da Escola de Agronomia da Universidade Federal da Bahia, 44.380-000, Cruz das Almas, BA

3 Pesquisador da Embrapa Mandioca e Fruticultura, CP 007, 44.380-000, Cruz das Almas, BA

4 Estudante do Curso de Agronomia da Universidade Federal da Bahia 
comerciais, também contribuindo, desta forma, para a conservação dos recursos genéticos.

Arruda \& Nolasco (1986) consideram que a existência de um grande número de espécies frutíferas vegetando no Brasil, principalmente no Nordeste, sem as informações necessárias sobre o seu desenvolvimento vegetativo, início de produção, época de floração, incidência de pragas e doenças, além da descrição botânica, constitui uma lacuna importante que deve ser preenchida o mais rapidamente possível.

Giacometti \& Goes (1986) comentam que o germoplasma de espécies frutíferas envolve genótipos selecionados e mantidos pelos agricultores, cultivares avançadas obtidas a partir de programas de melhoramento e, o mais importante, populações silvestres cujos produtos são colhidos e eventualmente comercializados. Segundo esses autores, a conservação do germoplasma destas espécies tem por objetivo manter indefinidamente a diversidade genética e garantir o maior número possível de genótipos para os programas de melhoramento genético.

Allard (1971) cita que a formação de bancos de germoplasma é fundamental na introdução de plantas, considerando-se esta um método de melhoramento, desde quando a importação de variedades superiores de outras áreas pode atingir os mesmos propósitos que aqueles de desenvolver variedades-elite a partir de programas de melhoramento genético. Este autor também argumenta que a introdução de germoplasma, no futuro, terá um papel de menor importância na produção de variedades com interesse comercial, mas será fundamental na criação de reservatórios de genes que ficarão à disposição dos melhoristas.

Song (1980), Alcazar (1983) e Camargo et al. (1974) consideram que o passo inicial para o desenvolvimento de um programa de melhoramento genético é a formação de uma coleção de genótipos, onde as espécies em estudo estejam representadas por diversos acessos, que deverão ser catalogados e avaliados, permitindo, inclusive, o intercâmbio de germoplasma entre instituições.

Formar um banco de germoplasma implica um custo relativamente alto, considerando todas as etapas de coleta, multiplicação, implantação e conservação do material no campo ao longo do tempo, exigindo a necessidade de recursos de forma ininterrupta. Diversos aspectos devem ser considerados na dinâmica da manutenção de uma coleção, começando por uma criteriosa caracterização morfológica, fenológica e de produtividade, tentando reduzir materiais duplicados e buscar disponibilizar alguns genótipos promissores diretamente para os agricultores. Vale ressaltar que há casos em que o aproveitamento dessas coleções se restringe basicamente a noticiários em meios de comunicação, na tentativa de justificar as ações de algumas instituições de pesquisa, de forma que os agricultores, principalmente os de baixa renda, mesmo aqueles de áreas próximas a esses repositórios de diversidade vegetal, não têm acesso a este germoplasma, o que poderia contribuir para melhorar a qualidade de vida desses produtores.

O elevado custo de manutenção de muitas coleções constitui um fator preocupante, verificando-se, em inúmeros casos, a falta de recursos em determinados períodos, normalmente provocados por alterações de prioridades, dependentes da política nacional e/ou estadual ou até de mudanças de dirigentes, que entendam a conservação de recursos genéticos como um tema de menor importância. Uma coleção de germoplasma, entretanto, não pode ficar na dependência de atitudes isoladas, que possam determinar o seu destino. Daí a necessidade do envolvimento do maior número possível de pessoas na conservação do patrimônio genético disponível, que pertence não só às gerações presentes, como também às futuras.

Grande parte das unidades de pesquisa encontra-se atualmente próxima a centros urbanos, o que leva sistematicamente a invasões destas áreas por moradores em busca de alimento, o que poderá comprometer os resultados experimentais, além de colocar em risco o processo de conservação de germoplasma, pela depredação das plantas.

Em vista dessas exposições, o envolvimento do agricultor no processo de conservação de germoplasma torna-se uma ação importante, pois seu comprometimento na execução desta tarefa acabará por interessar a todos os membros da comunidade em que tal ação se desenvolve, incluindo os jovens que, desde cedo, passarão a se sentir responsáveis pela conservação dos recursos naturais. Estas idéias devem ser transferidas gradativamente por meio de visitas de pesquisadores e educadores, despertando em todos a importância da preservação ambiental. Neste contexto, a introdução de espécies frutíferas na propriedade rural poderá, além de constituir uma nova fonte de renda, melhorar o nível alimentar do agricultor, em razão de um aumento qualitativo na disponibilidade de nutrientes. Estes genótipos estarão, assim, sendo conservados com maior interesse e segurança ao longo do tempo, evitando a dependência de recursos financeiros inseguros.

Fundamentando-se nestas questões, que constituem uma realidade na conservação de germoplasma, foi proposta a realização deste trabalho, que pretende contribuir com a conservação do patrimônio genético de frutíferas tropicais, segundo uma conotação prática, objetiva, com baixos custos e eficiente.

Parte deste trabalho está sendo realizada em área experimental da Escola de Agronomia da Universidade Federal da Bahia - AGRUFBA, localizada em Cruz das Almas, município do Recôncavo baiano, onde predominam solos do tipo Latossolo Amarelo, de textura média na camada de 0 a $30 \mathrm{~cm}$, sendo considerados de baixa fertilidade. A região encontra-se a uma altitude de $220 \mathrm{~m}$, apresenta temperatura e precipitação médias anuais de $24^{\circ} \mathrm{C} \mathrm{e} 1200 \mathrm{~mm}$, respectivamente, com umidade relativa do ar em torno de $80 \%$, estando a $12^{\circ} 40^{\prime} 39^{\prime \prime}$ de latitude sul e $39^{\circ} 06$ '23" de longitude oeste de Greenwich.

Outro segmento do trabalho está sendo conduzido em propriedades particulares, pertencentes a agricultores do município de São Felipe, também localizado no Recôncavo baiano. Inicialmente, foram selecionados dois agricultores que demonstraram pleno interesse em desenvolver a atividade, além de serem considerados pontos de referência na região, condição fundamental para a posterior divulgação do trabalho.

Agricultor I: Irineu Barbosa, 62 anos, natural de São Felipe, Bahia, casado, três filhos.

Propriedade: Fazenda Pau d'Alho, com área de 53,9 ha, ocupada principalmente com pastagens, possuindo pequena área com fruticultura, culturas de subsistência e 12 tarefas de Mata Atlântica.

Agricultor II: Clemente Alves, 70 anos, natural de São Felipe, 
Bahia, casado, três filhos.

Propriedade: Sítio com 10,9 ha, localizado na comunidade de Conceição Velha, ocupada com culturas de subsistência e algumas frutíferas, como jaqueira, fruta-pão e bananeiras.

Espécies frutíferas foram coletadas em diversas regiões do Estado da Bahia, na forma de sementes, sendo estas, após selecionadas, colocadas em sacos de polietileno, previamente cheios com uma mistura formada por terra vegetal e esterco de curral curtido. As mudas foram conduzidas no viveiro da AGRUFBA e transferidas para o campo ao atingir o porte apropriado. No campo, o espaçamento foi variável, dependendo da espécie considerada, sendo de $4 \mathrm{~m}$ x $4 \mathrm{~m}$ para aquelas de menor porte, como a ateira, gravioleira e pitangueira, e de até $8 \mathrm{~m}$ x $8 \mathrm{~m}$ no casos do jenipapeiro e abieiro.

As primeiras mudas foram levadas a campo em junho de 1996, tanto na AGRUFBA como nas áreas dos agricultores. A cada ano, nesta mesma época, que corresponde ao período chuvoso, a coleção é ampliada, com a introdução de novos acessos oriundos de coletas mais recentes. No momento do plantio, as mudas recebem uma adubação básica com esterco de curral curtido, numa dose de $2 \mathrm{~kg}$ por cova, acrescido de $100 \mathrm{~g}$ de superfosfato simples.

Normalmente, são realizadas três a quatro capinas manuais ao ano, a depender da incidência de plantas daninhas, e duas adubações em cobertura, utilizando cloreto de potássio (60 $\mathrm{kg} / \mathrm{ha}$ ) e uréia (40kg/ha), aplicando-se $100 \mathrm{~g}$ da mistura por planta.

No caso da umbucajazeira, levantamento de genótipos localizados em áreas de produtores foi iniciado em março de 2000, compreendendo as principais regiões produtoras do Estado da Bahia, que se concentram nos municípios de Santa Teresinha, Itatim, Castro Alves, Iaçu, Amargosa, Rafael Jambeiro, Santo Estevão, Tanquinho, Santa Bárbara, Milagres e Irará. Nas coletas, as plantas foram localizadas com o emprego do aparelho GPS (Global Position System). Os frutos coletados são encaminhados ao Laboratório de Tecnologia de Alimentos da Embrapa Mandioca e Fruticultura, onde são submetidos a análises físicas (comprimento, largura e peso de frutos, densidade da polpa e relação polpa/semente, teor de sólidos solúveis totais), químicas ( acidez total titulável, teor de vitamina $\mathrm{C}$ ) e físico-químicas $(\mathrm{pH})$, segundo metodologia recomendada pela A, O, A, C, (1995). Os genótipos que se destacarem como promissores a partir dessas avaliações serão coletados, propagados vegetativamente e conservados.

O segmento do trabalho, que inclui a participação do agricultor, conduzido no município de São Felipe, compreendia até a última avaliação realizada, em fevereiro de 2000, 22 espécies frutíferas, representadas por um total de 26 acessos, como se pode verificar na Tabela $1 . \mathrm{O}$ aspecto vegetativo das plantas indica que o manejo está sendo realizado de forma eficiente pelos agricultores, em comparação com o que se verifica atualmente na coleção instalada no campo experimental da AGRUFBA. Algumas espécies iniciaram a frutificação entre dois a três anos após a implantação, conforme se verificou com a gravioleira, pitangueira, fruta-do-conde e com a talineira. O sapotizeiro, por se tratar de material propagado de forma assexual, chegou a frutificar com apenas um ano após sua implantação em campo, o que despertou o interesse de toda a comunidade local e circunvizinhanças, desde quando esta planta tradicionalmente frutifica entre seis a oito anos após o plantio normalmente realizado por sementes.
Os frutos produzidos estão sendo comercializados no próprio sítio, ou na feira livre mais próxima, localizada na cidade de São Felipe. No caso da gravioleira e pitangueira, os frutos também estão sendo fornecidos a um pequeno fabricante de polpas, localizado acerca de $20 \mathrm{~km}$ do local de produção. A comercialização é realizada com o material excedente, pois parte considerável da colheita é consumida pelas próprias famílias de produtores, na forma natural, sucos, licores, além do consumo da polpa, que é armazenada após sua retirada.

O que mais desperta a atenção é a motivação dos agricultores vizinhos, que demonstram interesse em participar do programa, principalmente por se tratar de plantas desconhecidas para a comunidade, além da metodologia de propagação vegetativa utilizada para algumas fruteiras, a exemplo do sapotizeiro, que reduz substancialmente o tempo entre o plantio e o início de produção.

As visitas realizadas a estas coleções são acompanhadas por vários membros da comunidade local, que também pretendem participar do trabalho, além de solicitarem a presença de técnicos em suas propriedades, na tentativa de solucionar problemas com outras culturas. Verifica-se, assim, que o pequeno agricultor realmente é colocado em planos inferiores quando se trata de assistência técnica, principalmente em relação às informações geradas nos centros de pesquisa, a cujo acesso ainda têm dificuldades. A simples informação sobre a propagação de uma planta frutífera, por exemplo, pode contribuir de forma marcante para com o desempenho financeiro de uma família na zona rural, podendo promover a melhoria de sua qualidade de vida.

Os resultados referentes à conservação de germoplasma no campo experimental da AGRUFBA encontram-se registrados na Tabela 2, onde se observa a presença de 28 espécies frutíferas, num total de 52 acessos, cada qual representado por um número variável de plantas. Esta variação se deve a vários fatores, entre os quais a disponibilidade de material de propagação vegetativa e o porte, desde quando algumas espécies, como a sapucaieira, cajazeira, cajaraneira, jatobazeiro e o baruzeiro podem ultrapassar $15 \mathrm{~m}$ de altura, tornando difícil, mais tarde, sua manutenção.

Vale ressaltar que a coleção está aumentando a cada ano, à medida que as coletas vão disponibilizando novos acessos. Desta forma, a coleção, iniciada em 1995/1996, vem desse período em diante, nos meses de abril, maio e junho de cada ano, sendo sistematicamente ampliada.

As primeiras plantas a entrar em produção foram as do grupo das anonáceas, à exceção de um tipo de araticum coletado no município de Lagarto - SE, que floresce todos os anos, mas não frutifica, talvez por questão de adaptação, visto que sua região de origem apresenta um clima tendendo para semi-árido, ao contrário de Cruz das Almas, que apresenta elevada umidade. A primeira safra da cajazeira ocorreu em maio de 2000, cinco anos após o plantio, via sexuada, da mesma forma que o jenipapeiro.

Entre as mirtáceas, o jambo-rosa frutificou pela primeira vez em 1998, três anos após o plantio, via sexuada, enquanto a pitangueira começou a produzir logo aos dois anos. A cabeludinha e a grumixameira floraram pela primeira vez em março de 2000, aos cinco anos de idade. Vale ressaltar que as plantas presentes na coleção da AGRUFBA não têm recebido um manejo adequado devido à falta de recursos financeiros. Muitas vezes, verificouse o ataque de formigas, e as adubações e capinas normalmente foram atrasadas. Espera-se que, à medida que as produções de 
TABELA 1 - Relação de espécies frutíferas implantadas em junho de 1996 em propriedades particulares, município de São Felipe-Bahia.

\begin{tabular}{|c|c|c|c|}
\hline Espécie & Nom e vulgar & Nú merode acessos & Plantas/acesso \\
\hline Achras sapota & S apotizeiro & 01 & 30 \\
\hline A. bahiensis & Araticunzeiro & 01 & 02 \\
\hline A. muricata & Gravioleira & 03 & 10 \\
\hline A. reticulata & Fruta-do-conde & 01 & 03 \\
\hline Averrhoa bilimbi & B iri-birizeiro & 01 & 02 \\
\hline A. carambola & $\mathrm{C}$ aram boleira & 01 & 02 \\
\hline Chrysophyllum caim ito & $\mathrm{C}$ aim iteiro & 01 & 02 \\
\hline Eugenia brasiliensis & Grum ix am eira & 01 & 04 \\
\hline E. piriform is & Uvaia & 01 & 01 \\
\hline E. stipitata & A raçá-boi & 01 & 03 \\
\hline E. tom entos a & C abeludinha & 01 & 04 \\
\hline E. un iflora & Pitangueira & 02 & 20 \\
\hline Rollinia muscosa & T a line ira & 01 & 02 \\
\hline R. silvatica & Araticunzeiro & 01 & 02 \\
\hline
\end{tabular}

TABELA 2 - Relação de fruteiras implantadas no campo experimental da Escola de Agronomia da Universidade Federal da Bahia, em 1996. Cruz das Almas-Bahia.

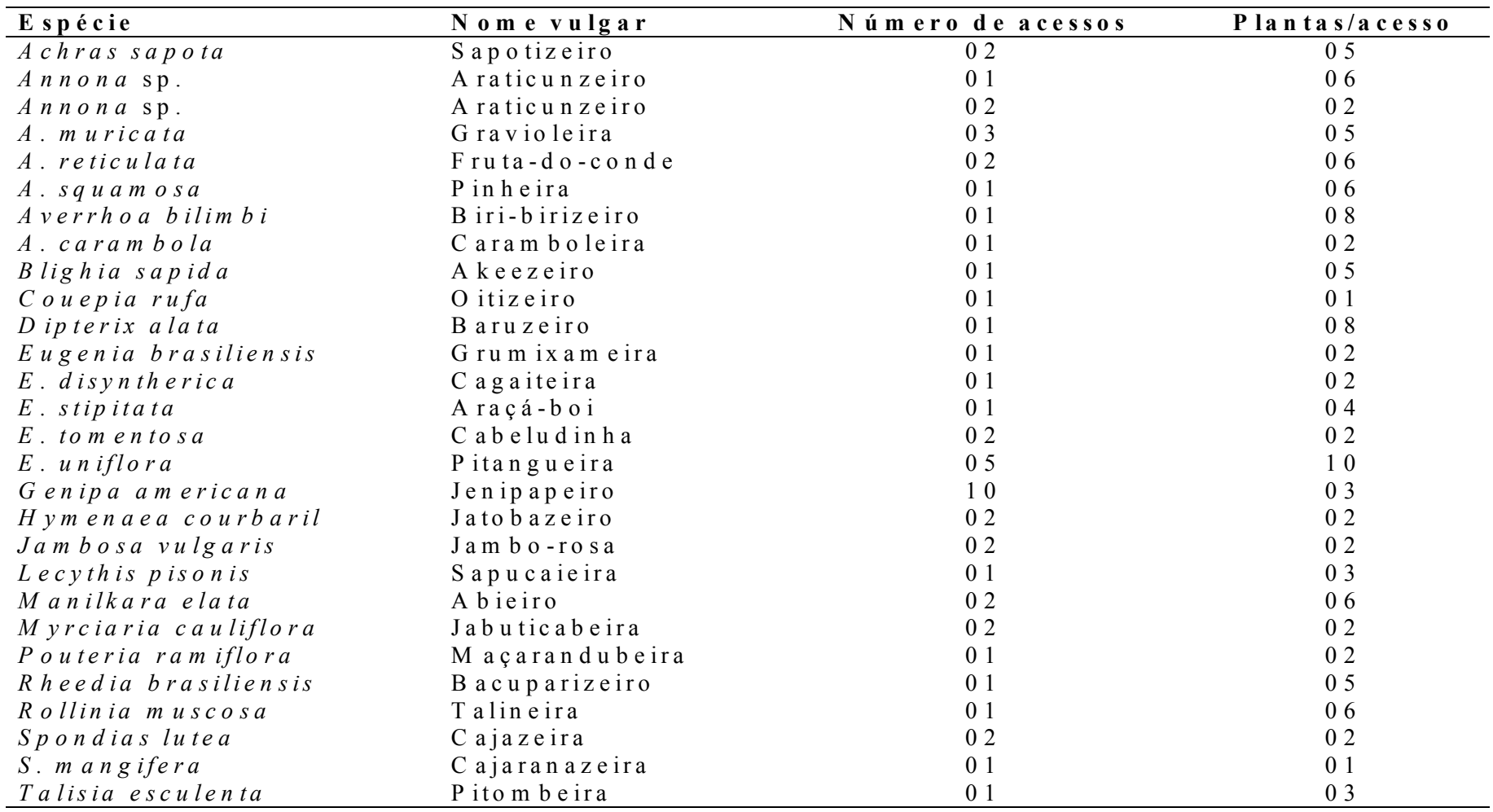

frutos aumentem, o resultado financeiro com a venda das mesmas possa auxiliar nos custos relativos à sua manutenção.

Como considerações finais, tem-se que:

1. A conservação de germoplasma de fruteiras tropicais em parceria com o agricultor é segura, apresenta custos relativamente baixos e as plantas têm-se mostrado bem conduzidas, mantendo-se sempre vigorosas.

2. A introdução de novas espécies no meio rural constitui uma fonte alternativa de renda para o agricultor, contribuindo para a melhoria da qualidade de vida de sua família.

3. A presença do técnico em visitas às coleções mantidas pelo produtor rural constitui um estímulo para a comunidade envolvida no processo de conservação, ajudando o agricultor na resolução de pequenos problemas em sua propriedade e diminuindo a distância entre a ciência e a realidade rural.

\section{REFERÊNCIAS BIBLIOGRÁFICAS}

ALCAZAR, J.T.E. Los recursos fitogenéticos; una investigación segura para el futuro. Madrid: Conselho Internacional de Recursos fitogenéticos, 1983.444p. 
ALLARD, R.W. Princípios do melhoramento genético das plantas. São Paulo: Edgard Blücher, 1971.381p.

A.O.A.C.-ASSOCIATION OF OFFICIAL ANALYTICAL CHEMISTS. Official methods of analysis. 16. ed. Arlington, 1995. $1141 \mathrm{p}$.

ARRUDA, R.J.S.; NOLASCO, F. Pomar matriz. Revista Brasileira de Fruticultura, Cruz das Almas, BA, v.6, n.1, p.63-70, 1986.

CAMARGO, C.P.; GREGG, B.R.; LINGER FELT, C.V. Banco
Nacional de Germoplasma: Necessidade de hoje, segurança de amanhã. Brasília, DF: AGIPLAN, 1974. 40p.

GIACOMMETI, D.C.; GOES, M. de. Conservação de germoplasma de espécies frutíferas pelo uso da biotecnologia. Revista Brasileira de Fruticultura, Cruz das Almas, BA, v.8, n.3, p.39-46, 1986.

SONG, L. Introducción al manejo de dados de germoplasma; curso de recursos genéticos. Pergamino, Argentina: INTA/ Estación Experimental Regional Agropecuária, 1980.9p. 